\title{
Evaluation of a Photosynthesis-Based Canopy Resistance Formulation in the Noah Land-Surface Model
}

\author{
Anil Kumar • Fei Chen · Dev Niyogi • \\ Joseph G. Alfieri • Michael Ek • Kenneth Mitchell
}

Received: 9 October 2009 / Accepted: 26 October 2010 / Published online: 16 November 2010

(C) Springer Science+Business Media B.V. 2010

\begin{abstract}
Accurately representing complex land-surface processes balancing complexity and realism remains one challenge that the weather modelling community is facing nowadays. In this study, a photosynthesis-based Gas-exchange Evapotranspiration Model (GEM) is integrated into the Noah land-surface model replacing the traditional Jarvis scheme for estimating the canopy resistance and transpiration. Using 18-month simulations from the High Resolution Land Data Assimilation System (HRLDAS), the impact of the photosynthesis-based approach on the simulated canopy resistance, surface heat fluxes, soil moisture, and soil temperature over different vegetation types is evaluated using data from the Atmospheric Radiation Measurement (ARM) site, Oklahoma Mesonet, 2002 International $\mathrm{H}_{2} \mathrm{O}$ Project (IHOP_2002), and three Ameriflux sites. Incorporation of GEM into Noah improves the surface energy fluxes as well as the associated diurnal cycle of soil moisture and soil temperature during both wet and dry periods. An analysis of midday, average canopy resistance shows similar day-to-day trends in the model fields as seen in observed patterns. Bias and standard deviation analyses for soil temperature and surface fluxes show that GEM responds somewhat better than the Jarvis scheme, mainly because the Jarvis approach relies on a parametrised minimum canopy resistance and meteorological variables such as air temperature and incident radiation. The analyses suggest that adding a photosynthesis-based
\end{abstract}

\footnotetext{
A. Kumar · F. Chen

National Center for Atmospheric Research, Boulder, CO, USA

A. Kumar · D. Niyogi · J. G. Alfieri

Purdue University, West Lafayette, IN, USA

M. Ek · K. Mitchell

National Center for Environmental Prediction, Camp Springs, MD, USA

A. Kumar $(\varangle)$

Hydrological Science Branch (Code-614.3), NASA Goddard Space Flight Center,

Greenbelt, MD 20771, USA

e-mail: anil.kumar@nasa.gov

Present Address:

J. G. Alfieri

Hydrology and Remote Sensing Laboratory, USDA-ARS, Beltsville, MD, USA
} 
transpiration scheme such as GEM improves the ability of the land-data assimilation system to simulate evaporation and transpiration under a range of soil and vegetation conditions.

Keywords Canopy resistance - Evapotranspiration - Land data assimilation system · Noah land-surface model $\cdot$ Photosynthesis $\cdot$ Surface energy flux

\section{Introduction}

Correctly representing the role of land-atmosphere exchange processes remains one challenging problem in weather and climate modelling (Pielke and Niyogi 2010). The misrepresentation of surface processes may result in significant errors in both short-term and long-term forecasts (Chen et al. 2007). This is because land-surface models combine information describing the surface boundary-layer, radiation, and precipitation forcing with information describing the surface properties and state to provide the heat, moisture and momentum fluxes needed as lower boundary conditions for numerical weather prediction (NWP) models. Based on numerous studies (Beljaars et al. 1996; Betts et al. 1997; Chen et al. 1997; Ek et al. 2003; Trier et al. 2008), the improvement of one- to five-day predictions of boundarylayer development, cloud formation, precipitation, and surface meteorology depends heavily on improving the representation of surface processes and the initialization of soil moisture. Moreover, due to the linkages between mesoscale and large-scale processes, it is hypothesised that the importance of improving the representation of surface processes increases as the model resolution increases (Holt et al. 2006).

Many operational models used by the European Centre for Medium-Range Weather Forecasts (ECMWF), the National Centre for Environmental Prediction (NCEP), and MeteoFrance (IAGL) utilise the so-called Jarvis (1976) scheme in conjunction with Penman-Monteith (1965) type relationships to calculate transpiration. One of these models is the Noah land-surface model (Noah), which is a core component of the Weather Research and Forecasting (WRF) model, as well as a number of land data assimilation systems such as the High Resolution Land Data Assimilation System (HRLDAS; Chen et al. 2007) and North American Land Data Assimilation System (NLDAS; Mitchell et al. 2004).

In the Jarvis scheme, the canopy resistance $\left(R_{c}\right)$ is calculated as a function of the minimum canopy resistance $\left(R_{c \min }\right)$ and a number of environmental stress functions. Chen and Dudhia (2001) found that Noah was sensitive to the specification of $R_{c} \min$. More recently, Alfieri et al. (2008) concluded that the use of the Jarvis scheme in Noah can result in significant errors in the flux estimates because it does not consider many environmental factors affecting $R_{c}$; they further concluded that this limitation of the Jarvis scheme could not be overcome using a constant parametrisation of $R_{c}$ min. Also, studies by Niyogi and Raman (1997), Alapaty et al. (1997), and Cooter and Schwede (2000) suggest that uncertainty in $R_{c}$ min can significantly alter the simulated hydrological cycle budget and result in a misrepresentation of boundary-layer processes that can then affect the coupled model forecast. Hence, as pointed out by Mitchell (2005), improving the ability of Noah to predict transpiration is of immediate relevance to the NWP community.

The accuracy of transpiration estimates derived from the Penman-Monteith relationship depends heavily on the robustness of the values of $R_{c}$, because $R_{c}$ is a highly dynamic variable that represents the complex inter-relationships between the plant physiological processes and environmental processes controlling the water vapor flux from the vegetation. One example of the controlling processes is the photosynthetic pathway. Due to differences in biochemical pathways and physiology, plants that utilise the more common $\mathrm{C} 3$ photosynthetic pathway 
have a very different response to light, temperature ambient $\mathrm{CO}_{2}$ concentration, and other environmental forcings than those that utilise the $\mathrm{C} 4$ photosynthetic pathway (Niyogi et al. 1998). Because of these differences, the impacts of $\mathrm{C} 3$ and $\mathrm{C} 4$ plants on the water, carbon, and energy cycles also differ.

Niyogi et al. (1998, 2008) developed the Gas-exchange Evapotranspiration Model (hereafter GEM) based on the Ball-Berry-Collatz scheme (Ball et al. 1987), which determines $R_{c}$ as a function of $\mathrm{CO}_{2}$ assimilation rate, surface temperature, and ambient temperature (Collatz et al. 1991, 1992; Sellers et al. 1996a,b). The impacts of GEM on a grid-scale surface energy balance and diurnal atmospheric feedback were evaluated in Niyogi et al. (2008). The impact of GEM on simulations of summer-season surface heat fluxes using Noah in an offline mode is discussed in Kumar et al. (2008). The objective of the present study is to determine the impact of $R_{c}$ on surface fluxes and soil moisture, and to evaluate both the Jarvis scheme and GEM within Noah using long-term uncoupled simulations and field data. Since GEM should capture the differences in the response of $\mathrm{C} 3$ and $\mathrm{C} 4$ plants to ambient environmental conditions, it is expected that the combined Noah-GEM model will be better able to represent land-atmosphere exchange processes than the default version of Noah.

The Noah land-surface model, Jarvis scheme, and GEM are briefly described in Sects. 2.1, 2.2, and 2.3, respectively. Section 2.4 describes the model configuration and domain while Sect. 2.5 discusses the field observations used for validation. The results are presented in Sect. 3 followed by the conclusions in Sect. 4.

\section{Description of the Noah Land-Surface Model and $\boldsymbol{R}_{c}$ Formulations}

\subsection{The Noah Land-Surface Model}

The Noah land-surface model is based on coupling the diurnally dependent Penman potential evaporation approach of Mahrt and Ek (1984) with the multilayer soil model of Mahrt and Ek (1984) and the canopy model of Pan and Mahrt (1987). The canopy resistance approach of Noilhan and Planton (1989) and Jacquemin and Noilhan (1990) was implemented within the Noah land-surface model framework by Chen et al. (1996) and Chen and Dudhia (2001). The model's thermodynamics and hydrology formulation is described in Chen and Dudhia (2001). In general, Noah utilises a combined canopy-surface layer and four soil layers. The soil layers, which have thicknesses of $0.1,0.3,0.6$, and $1 \mathrm{~m}$, respectively from the surface downward, represent the soil to a total depth of $2 \mathrm{~m}$. While the rooting depth is specified according to the vegetation type, in general, the upper layers represent a 1-m rooting zone while the deepest layer acts a moisture reservoir.

In Noah, the total evaporation $(E)$ is determined as the sum of (a) direct evaporation from the surface $\left(E_{d i r}\right)$, (b) evaporation of intercepted rainfall from the canopy $\left(E_{c}\right)$, and (c) transpiration from the canopy $\left(E_{t}\right)$. The total evaporation $(E)$ is thus given as

$$
E=E_{d i r}+E_{c}+E_{t} .
$$

As described in detail by Ek et al. (1991), the calculation of $E_{t}$, the main focus of our study, is conducted as follows:

$$
E_{t}=\sigma_{f} E_{p} B_{c}\left[1-\left(\frac{W_{c}}{S}\right)^{n}\right]
$$

where $\sigma_{f}$ is the green vegetation fraction, $E_{p}$ is potential evaporation, $W_{c}$ is the amount of water intercepted by the canopy, $S$ is the maximum water capacity of the canopy 
(specified as $0.5 \mathrm{~mm}$ ), and $n$ is a constant (specified as 0.5 ). $B_{c}$ is a function of $R_{c}$ and is calculated as

$$
B_{c}=\frac{1+\Delta / R_{r}}{1+R_{c} C_{h}+\Delta / R_{r}}
$$

where $\Delta$ is the slope of the temperature-saturation water vapour curve, $R_{r}$ is a dimensionless function of temperature and pressure, and $C_{h}$ is the surface exchange coefficient for heat and moisture. The calculation of $R_{c}$ using the Jarvis scheme and GEM is discussed in Sects. 2.2 and 2.3 , respectively.

Surface properties such as vegetation type, albedo, leaf area index (LAI), and roughness length are parametrised in Noah using a "look-up" table keyed to a 24-category United States Geological Survey (USGS) land-cover dataset (Table 1). Soil hydraulic properties such as the slope of the water retention curve are determined in accordance with Cosby et al. (1984) using parameters specified as a function of the 16-category soil texture scheme (Table 2) developed by Miller and White (1998). The various atmospheric and surface forcings required by Noah are documented in Chen et al. (2007).

\subsection{The Jarvis Scheme in Noah}

The Jarvis scheme, which is implemented in Noah following Jacquemin and Noilhan (1990), estimates $R_{c}$ according to

$$
R_{c}=\frac{R_{c \min }}{\operatorname{LAI}\left(F_{1} F_{2} F_{3} F_{4}\right)}
$$

where $R_{c \text { min }}$ is the minimum canopy resistance, $L A I$ is the leaf area index, and $F_{1}, F_{2}, F_{3}$, and $F_{4}$ are weighting functions representing the effects of plant stress due solar radiation, humidity, soil moisture content, and air temperature, respectively, on $R_{c}$. As is described in detail in Chen and Dudhia (2001), these environmental stress functions are defined as follows:

$$
F_{1}=\frac{R_{c \min } / R_{c \max }+f}{1+f}
$$

with $f=0.55 \frac{R_{g}}{R_{g l}}\left(\frac{2}{L A I}\right)$,

$$
\begin{gathered}
F_{2}=\frac{1}{1+h_{s}\left[q_{s}\left(T_{a}\right)-q_{a}\right]}, \\
F_{3}=1-0.0016\left(T_{\text {ref }}-T_{a}\right)^{2},
\end{gathered}
$$

and

$$
F_{4}=\sum_{i=1}^{N_{R O O T}} \frac{\left(\theta_{i}-\theta_{\text {wilt }}\right) d_{i}}{\left(\theta_{\text {ref }}-\theta_{\text {wilt }}\right) d_{\text {tot }}},
$$

where $R_{c \max }$ is the maximum or cuticular canopy resistance, $R_{g l}$ is the minimum solar radiation necessary for photosynthesis (transpiration) to occur, $R_{g}$ is the incident solar radiation, $h_{s}$ is a parameter associated with the water vapour deficit, $q_{s}\left(T_{a}\right)-q_{a}$ represents the water vapour deficit, $T_{r e f}$ is the optimal air temperature for photosynthesis, $T_{a}$ is the air temperature, $\theta_{i}$ is the soil moisture content of the $i$ th soil layer, $\theta_{\text {wilt }}$ is the wilting point soil moisture, $\theta_{\text {ref }}$ is the field capacity soil moisture, $d_{i}$ is the thickness of the $i$ th soil layer, and $d_{t o t}$ is the 


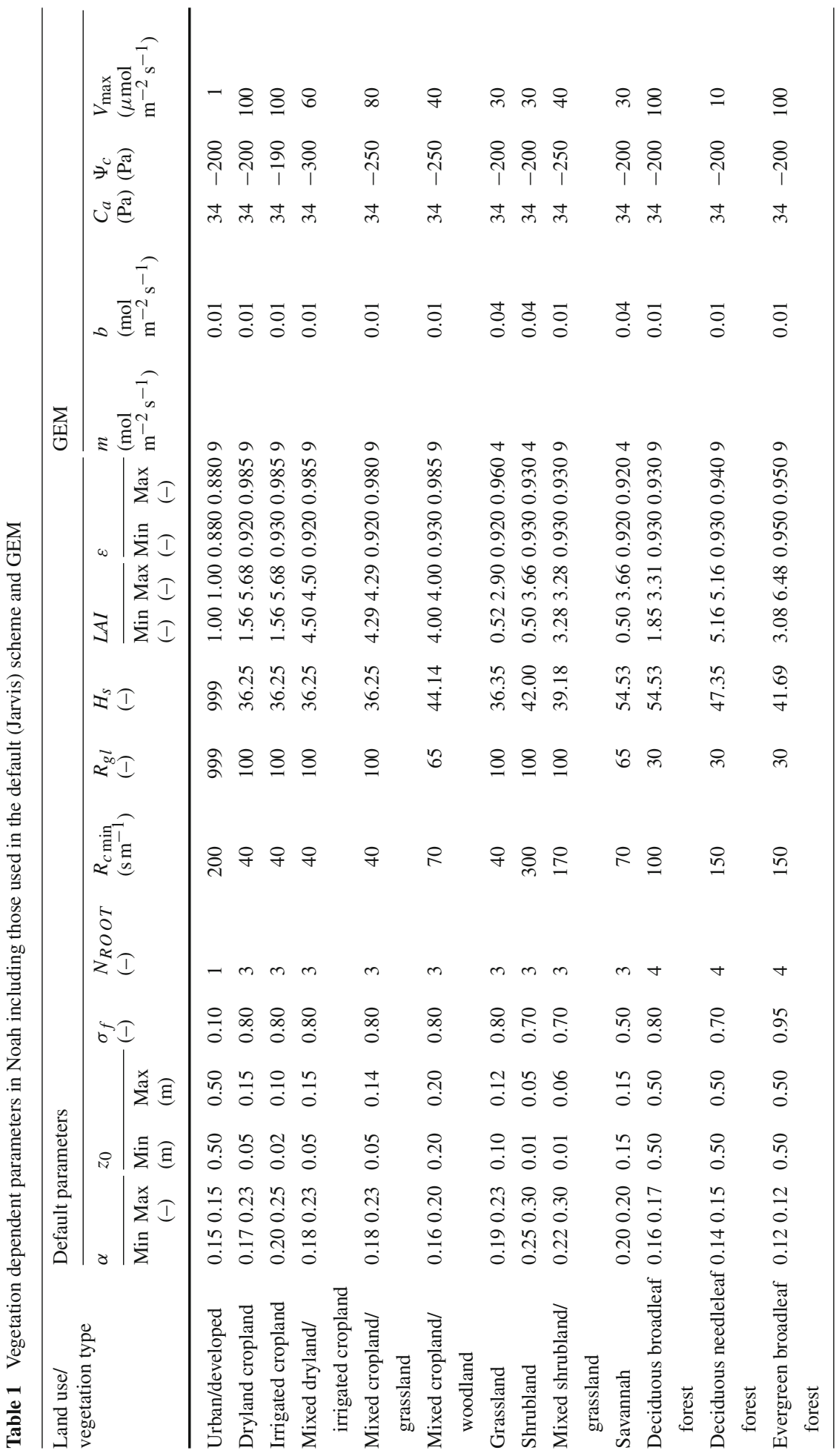




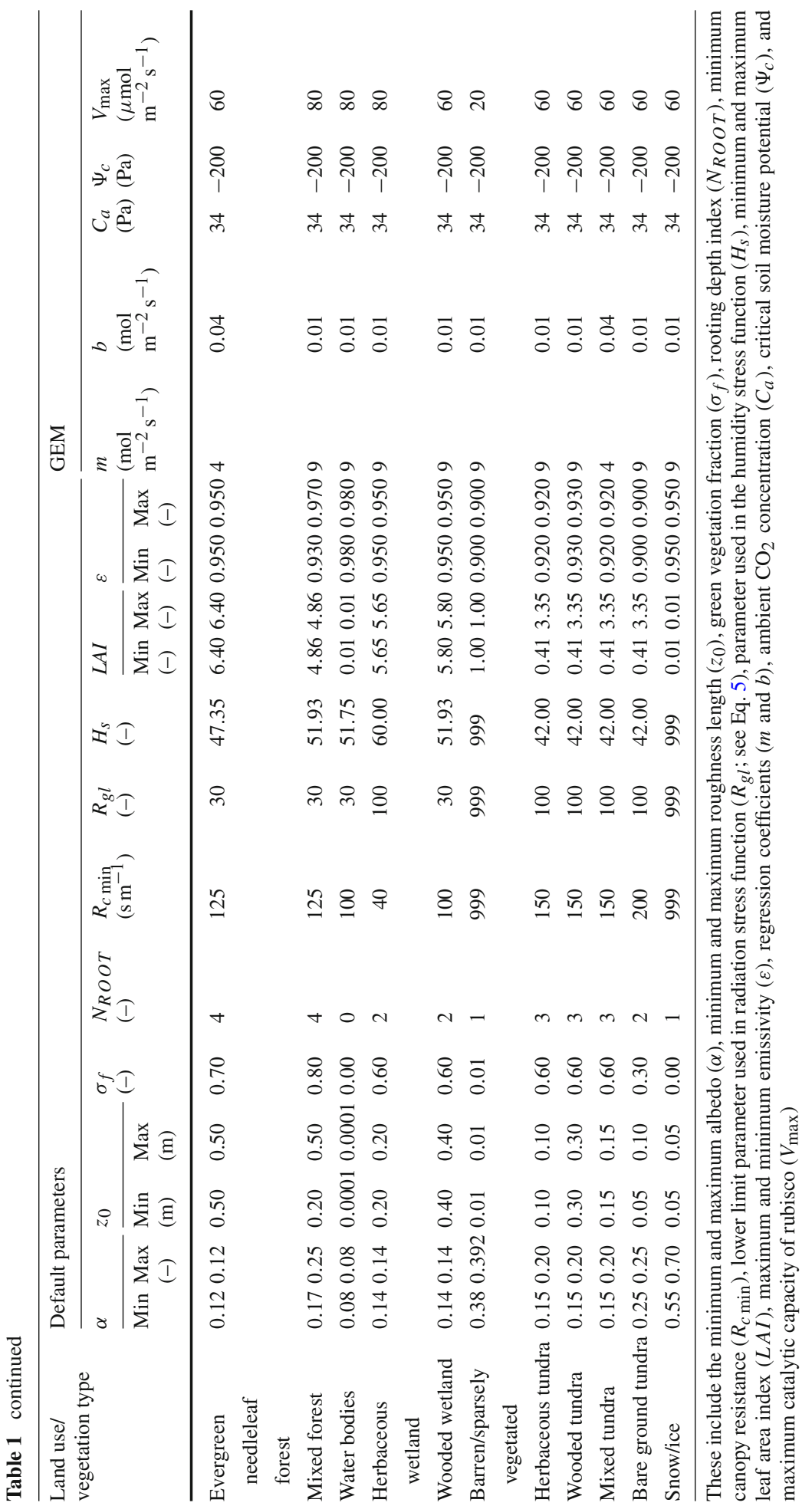


Table 2 Soil parameters in Noah

\begin{tabular}{|c|c|c|c|c|c|c|c|c|}
\hline Soil types & $B$ & $\theta_{\text {sat }}$ & $\theta_{\text {ref }}$ & $\begin{array}{l}\Psi_{\text {sat }} \\
(\mathrm{m})\end{array}$ & $\begin{array}{l}k_{s a t} \\
\left(\mu \mathrm{ms}^{-1}\right)\end{array}$ & $\begin{array}{l}D_{s_{a t}}{ }_{\left(\mathrm{mm}^{2} \mathrm{~s}^{-1}\right)}\end{array}$ & $\theta_{\text {wilt }}$ & $Q$ \\
\hline Sand & 2.79 & 0.339 & 0.236 & 0.069 & 1.07 & 0.608 & 0.010 & 0.92 \\
\hline Loamy sand & 4.26 & 0.421 & 0.383 & 0.036 & 14.10 & 5.140 & 0.028 & 0.82 \\
\hline Sandy loam & 4.74 & 0.434 & 0.383 & 0.141 & 5.23 & 8.050 & 0.047 & 0.60 \\
\hline Silty loam & 5.33 & 0.476 & 0.360 & 0.759 & 2.81 & 23.900 & 0.084 & 0.25 \\
\hline Silt & 5.33 & 0.476 & 0.383 & 0.759 & 2.81 & 23.900 & 0.084 & 0.10 \\
\hline Loam & 5.25 & 0.439 & 0.329 & 0.355 & 3.38 & 14.300 & 0.066 & 0.40 \\
\hline Sandy clay loam & 6.66 & 0.404 & 0.314 & 0.135 & 4.45 & 9.900 & 0.067 & 0.60 \\
\hline Silty clay loam & 8.72 & 0.464 & 0.387 & 0.617 & 2.04 & 23.700 & 0.120 & 0.10 \\
\hline Clay loam & 8.17 & 0.465 & 0.382 & 0.263 & 2.45 & 11.300 & 0.103 & 0.35 \\
\hline Sandy clay & 10.73 & 0.406 & 0.338 & 0.098 & 7.22 & 18.700 & 0.100 & 0.52 \\
\hline Silty clay & 10.39 & 0.468 & 0.404 & 0.324 & 1.34 & 9.640 & 0.126 & 0.10 \\
\hline Clay & 11.55 & 0.468 & 0.412 & 0.468 & 0.97 & 11.200 & 0.138 & 0.25 \\
\hline Organic material & 5.25 & 0.439 & 0.329 & 0.355 & 3.38 & 14.300 & 0.066 & 0.05 \\
\hline Water & 0.00 & 1.000 & 0.000 & 0.000 & 0.00 & 0.000 & 0.000 & 0.60 \\
\hline Bedrock & 2.79 & 0.200 & 0.170 & 0.069 & 141.00 & 136.000 & 0.006 & 0.07 \\
\hline Other & 4.26 & 0.421 & 0.283 & 0.036 & 14.10 & 5.140 & 0.028 & 0.25 \\
\hline Playa & 11.55 & 0.468 & 0.454 & 0.468 & 0.97 & 11.200 & 0.030 & 0.60 \\
\hline Lava & 2.79 & 0.200 & 0.170 & 0.069 & 141.00 & 136.000 & 0.006 & 0.52 \\
\hline White sand & 2.79 & 0.339 & 0.236 & 0.069 & 1.07 & 0.608 & 0.010 & 0.92 \\
\hline
\end{tabular}

$B$ is a curve fitting parameter that relates soil water potential and water content, $\theta_{\text {sat }}$ is the saturation soil moisture content, $\theta_{\text {ref }}$ is the field capacity soil moisture content, $\Psi_{\text {sat }}$ is the saturation soil potential, $k_{s a t}$ is the saturation soil conductivity, $D_{\text {sat }}$ is the saturation soil diffusivity, $\theta_{\text {wilt }}$ is the wilting point soil moisture content, and $Q$ is the fractional quartz content of the soil

total thickness of the rooting depth. The parameter values used by Noah are given in Tables 1 and 2 .

\subsection{The Gas-Exchange Evapotranspiration Model in Noah}

The Jarvis scheme has a number of limitations that are discussed in Niyogi et al. (2008) and Alfieri et al. (2008), which are expected to be overcome by the use of the physically-based GEM. In the coupled Noah-GEM (Niyogi et al. 2008), the Jarvis scheme is replaced with the Ball-Berry-Collatz approach (Ball et al. 1987), which uses robust parameters that do not vary significantly from their basal values (Collatz et al. 1991) and can be measured either in the laboratory or in the field (Ball et al. 1987). GEM estimates $R_{c}$ according to:

$$
R_{c}=\frac{1}{\operatorname{LAI}\left(m \frac{A r_{s}}{C_{s}}+b\right)}
$$

where $A$ is the carbon assimilation, $r_{s}$ is the leaf-level relative humidity, $C_{S}$ is the leaf-level $\mathrm{CO}_{2}$ concentration, and $m$ and $b$ are linear coefficients that depend on the vegetation type and photosynthetic pathway (Sellers et al. 1996b; Niyogi et al. 2008). In GEM, the estimation of the different parameters, particularly the carbon assimilation $\left(A_{n}\right)$ term, follows the Collatz et al. (1992) scheme. The photosynthesis rate is estimated following Sellers et al. (1996a). 
The key vegetation-dependent parameters in GEM (Table 1) include the linear coefficients $m$ and $b$, ambient $\mathrm{CO}_{2}$ concentration $\left(C_{a}\right)$, critical soil moisture potential $\left(\psi_{c}\right)$, and the maximum catalytic capacity of rubisco $\left(V_{\max }\right)$. The root zone soil moisture content $\left(W_{2}\right)$ is calculated in GEM as a weighted average of the dynamically obtained soil moisture from Noah. The modelled soil moisture for each of the root zone soil layers is weighted by the thickness of the corresponding layer to obtain $W_{2}$ as follows:

$$
W_{2}=\sum_{i=1}^{N_{R O O T}} \frac{\theta_{i} d_{i}}{d_{t o t}} .
$$

The effective change in the catalytic capacity of rubisco $\left(V_{m}\right)$ is calculated as a function of $W_{2}$ according to Calvet et al. (1998) as

$$
V_{m}=V_{\max } f(T) f\left(W_{2}\right) 2.1^{Q t}
$$

where $f\left(W_{2}\right)$ is computed as

$$
f\left(W_{2}\right)=\frac{W_{2}-\theta_{\text {wilt }}}{\theta_{\text {ref }}-\theta_{\text {wilt }}} .
$$

Following Anderson et al. (2000), the assimilation rate $\left(A_{n}\right)$ is adjusted for changes in the environmental conditions by scaling the unstressed value by a moisture stress factor $\left(S_{m}\right)$ as

$$
S_{m}=1-\left[f\left(W_{2}\right)\left(0.03^{-1 / B}-1.5^{-1 / B}\right)+1.5^{-1 / B}\right]^{-B}
$$

where $B$ is the slope of the soil moisture/water retention curve.

The Ball-Berry approach was chosen rather than the Leuning (1995) and the Kim and Verma (1990) canopy resistance approaches, which use the vapour pressure deficit as a driver, mainly because of the direct linear relationship between canopy resistance and relative humidity noted in Niyogi et al. (1998).

\subsection{The High-Resolution Land Data Assimilation System Configuration and Domain}

The numerical experiments were conducted using the uncoupled Noah/HRLDAS model. The HRLDAS framework (Chen et al. 2007) was selected for this investigation because it is capable of capturing the spatial variability of the soil and vegetation at scales ranging from 1 to $10 \mathrm{~km}$, the spatial scale typical of the mesoscale applications planned for the WRF system. For the simulations used here, HRLDAS was run from 1 January 2001 to 30 June 2002 with $550 \times 400$ grid points at a 4 - $\mathrm{km}$ resolution. The model domain over the continental United States (Fig. 1) represented a broad range of vegetation types including dry-land and cropland pasture $(22 \%)$, deciduous broadleaf forest (14\%), grass (13\%), cropland-grassland mosaic $(12 \%)$, cropland-woodland mosaic $(10 \%)$, evergreen needle-leaf forest $(11 \%)$, mixed forest $(5 \%)$, savannah $(3 \%)$, and urban $(1 \%)$.

The HRLDAS simulations used the following atmospheric forcing and surface conditions (Chen et al. 2007): (i) hourly 4- km NCEP Stage-IV rainfall analysis, (ii) 0.5 degree Geostationary Operational Environmental Satellite (GOES) gridded shortwave radiation, a product jointly developed by NESDIS/NOAA and the University of Maryland, (iii) other atmospheric forcing conditions from model-based analyses, (iv) 1-km United States Geological Survey (USGS) land-use map, and (v) 1-km State Soil Geographic Database (STASGO) soil texture map. HRLDAS output included profiles of soil moisture and soil temperature for four model soil layers $(0.1,0.3,0.6$, and $1.0 \mathrm{~m})$, surface sensible $(H)$ and latent heat fluxes $(L E)$, surface skin temperature $\left(T_{s}\right)$, runoff, and water table recharge (Table 3$)$. 


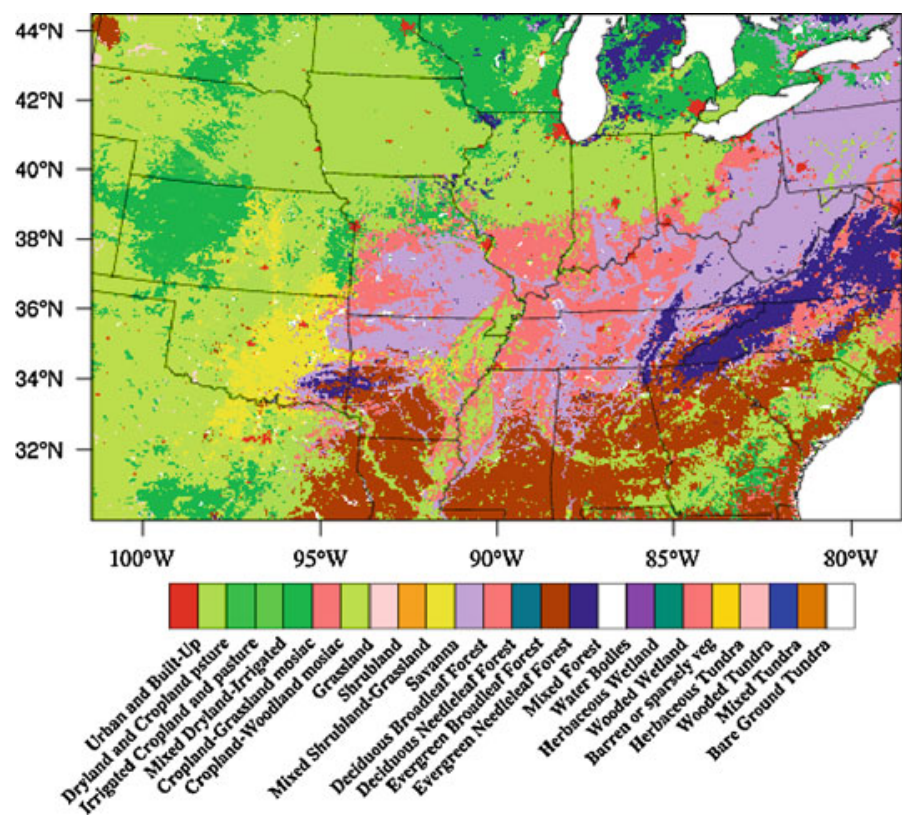

Fig. 1 Land-use categories and model domain

Table 3 Bias and mean for soil temperature $(\mathrm{K})$ at $50-\mathrm{mm}$ soil depth at an ARM (Plevna, Kansas) and Ameriflux (Mead, Nebraska) site for 1 through 29 June 2002

\begin{tabular}{lllllll}
\hline \multirow{2}{*}{$\begin{array}{l}\text { Soil temperature } \\
(\mathrm{K}) \text { - at sites }\end{array}$} & Bias Jarvis/GEM & \multicolumn{2}{l}{ Standard deviation } & \multirow{2}{*}{ Mean observation } & Mean Jarvis/GEM \\
\cline { 2 - 5 } & & Obs & Jarvis & GEM & \\
\hline Plevna & $1.02 /-0.5$ & 3.63 & 4.78 & 3.78 & 298.935 & $299.958 / 298.376$ \\
Mead & $2.031 / 1.35$ & 2.66 & 3.71 & 3.31 & 297.077 & $299.108 / 298.433$ \\
\hline
\end{tabular}

\subsection{Model Verification Data}

Observational data from the 2002 International $\mathrm{H}_{2} \mathrm{O}$ Project (IHOP_2002), Oklahoma Mesonet, U.S Department of Energy Atmospheric Radiation (ARM) sites, and Ameriflux sites were used to evaluate the model output. Conducted between 13 May and 25 June 2002 over the Southern Great Plains of the U.S.A., the IHOP_2002 field project investigated surface fluxes and micrometeorological conditions over several land-use types including winter wheat, grasslands, and bare soil (Weckwerth et al. 2004; LeMone et al. 2007a,b). The turbulent flux data, which were obtained using the eddy-covariance method, from Site 5 near Spivey, Kansas, and Site 6 near Conway Springs, Kansas, were used here. Both sites were cropped with winter wheat. Soil moisture and temperature data collected at 80 of the 110 automated stations that make up the Oklahoma Mesonet (Brock et al. 1995; Shafer et al. 2000) were also used to evaluate the model simulations. Detailed information about this Mesonet can be found at http://www.mesonet.org. The third dataset used to evaluate the model output was from the ARM site located in a grassland near Plevna, Kansas. To verify model results over other vegetation types, observations from three Ameriflux sites (Baldocchi et al. 2000): Niwot Ridge (Colorado), Mead (Nebraska) and Duke Hardwood Forest (North Carolina) 
were used. Data from other Ameriflux sites, such as that in Ponca, Oklahoma, that might have been useful for evaluating the effects of replacing the Jarvis scheme with GEM, were not available for the 2002 summer season.

\section{Results and Discussion}

\subsection{Analysis of Canopy Resistance}

As can be seen in Fig. 1, grasslands are the prevailing land-cover type across the western portion of the model domain. In contrast, the land cover across the eastern part of the domain, which consists of a mixture of forested, cropped, grassland, and savannah landscapes, is much more diverse. The impact of the method used to calculate $R_{c}$ on the modelled fluxes, skin temperature, and $R_{c}$ can be seen in Fig. 2, which shows the model output for each of these variables along an east-west transect at $36^{\circ} \mathrm{N}$ latitude. The difference between the turbulent energy fluxes derived from the Jarvis scheme and GEM are typically between 50 and $100 \mathrm{~W} \mathrm{~m}^{-2}$ over forested and cropped surfaces; a smaller difference is seen over savannah. The differences in the surface fluxes were primarily due to differences in $R_{c}$ from the two schemes. The resistance from the Jarvis scheme and GEM differed by $50-100 \mathrm{~s} \mathrm{~m}^{-1}$ over cropped and forested areas. The differences in $R_{c}$ also affected the skin temperature such that when the difference in the modelled $R_{c}$ was large $\left(50-200 \mathrm{~s} \mathrm{~m}^{-1}\right)$ the skin temperature differed by $2-3 \mathrm{~K}$.

To further characterize the differences in the model output when the different methods for estimating $R_{c}$ were used, the differences in $L E$, evapotranspiration (ET), and skin temperature were evaluated over the whole of the model domain (Fig. 3). Overall, due to the lower estimates of $R_{c}$ typically produced by the Jarvis scheme, $L E$ and ET were larger with the default version of Noah as compared to Noah-GEM. The skin temperature calculated by the default version of Noah also tended to be lower than that calculated by the version of the model incorporating GEM. This was particularly true over the western half of the model domain, which was dominated by grassland and cropland. Over the eastern portion of the model domain, a lower $R_{c}$ estimate from Noah-GEM resulted in a $50-100 \mathrm{~W} \mathrm{~m}^{-2}$ increase in $L E$ and a $1-2 \mathrm{~K}$ decrease in modelled skin temperature. The differences between the estimates of $R_{c}$ from the two methods could be traced, at least in part, to the ability of Noah-GEM to better distinguish between different vegetation types and to better represent their response to ambient environmental conditions.

Since $R_{C}$ is a difficult quantity to measure, few successful long-term observational studies have been conducted to understand its variability (Avissar 1993). As a result, the modelled summertime $R_{c}$ was evaluated against estimates from the literature. Figure 4 shows the average midday (0900-1500 LST) estimates of $R_{c}$ across the whole of the model domain from both the Jarvis scheme and GEM for the four main land cover types in the model domain: grassland, cropland, forest, and shrubland. Over grasslands, the average midday $R_{c}$ from GEM was from 250 to $350 \mathrm{~s} \mathrm{~m}^{-1}$ while their values produced by the Jarvis scheme were between 100 and $300 \mathrm{~s} \mathrm{~m}^{-1}$. Wilson et al. (2002) found the mean midday value of $R_{c}$ ranged between 200 and $500 \mathrm{~s} \mathrm{~m}^{-1}$ at the Little Washita (Kansas) during the summer months. For broadleaf deciduous forest, the average midday $R_{c}$ was 70 and $90 \mathrm{~s} \mathrm{~m}^{-1}$, respectively, for GEM and the Jarvis scheme. These estimates of $R_{c}$ are consistent with values reported by both Dorman and Sellers (1989), who calculated a range of $R_{c}$ between 50 and $100 \mathrm{~s} \mathrm{~m}^{-1}$ using the Simple Biosphere model, and Nemani and Running (1989) who determined $R_{C}$ ranged 

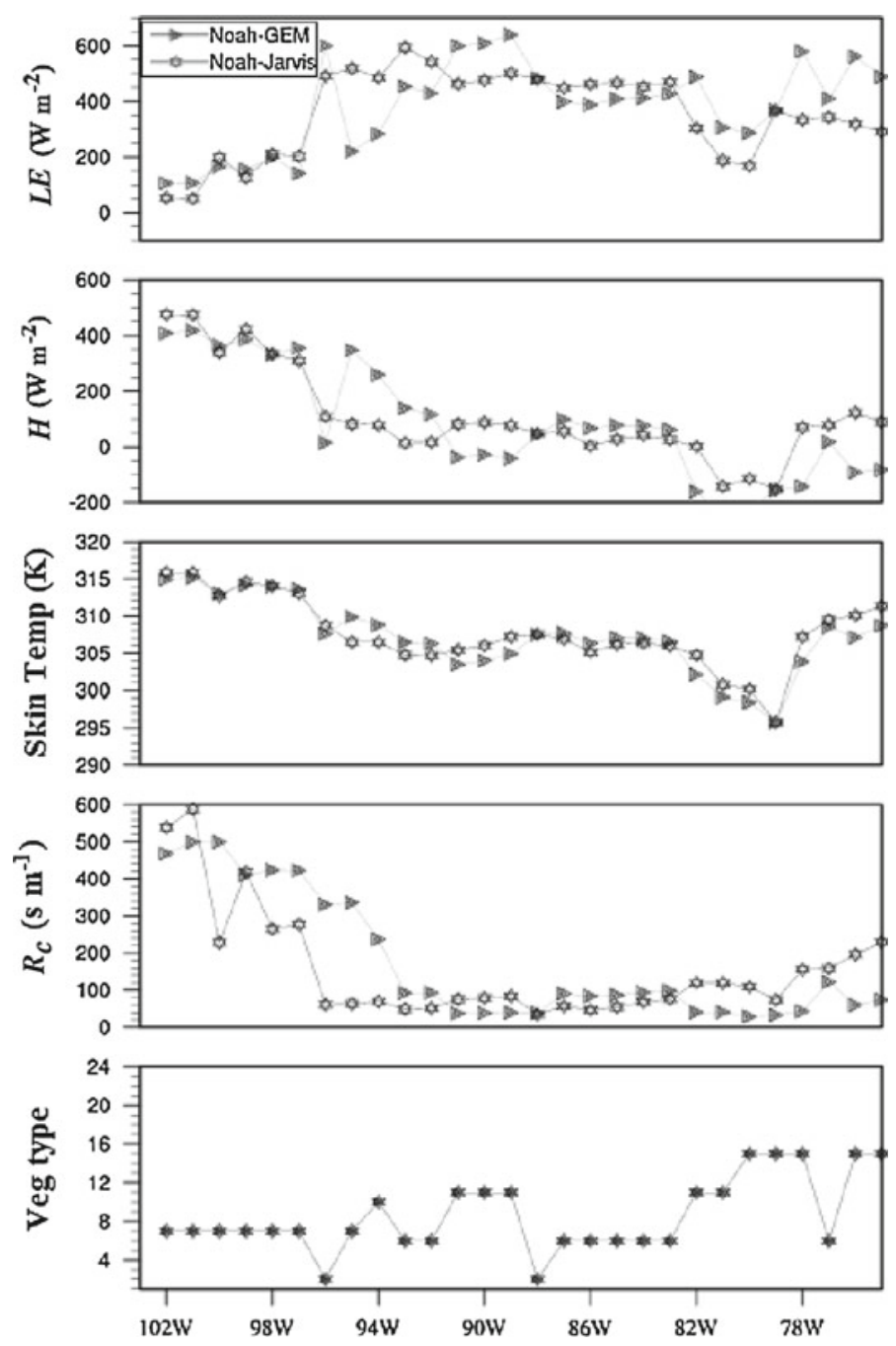

Fig. 2 West-east cross-section at $36^{\circ} \mathrm{N}$ latitude: Jarvis (open star) and GEM (closed triangle)

between 50 and $300 \mathrm{~s} \mathrm{~m}^{-1}$ over the Lubrecht Experimental Forest (Montana). Similarly, the $R_{c}$ estimates for coniferous forest from both GEM and the Jarvis scheme fall within the range of 20-200 s m${ }^{-1}$ reported in the literature (McNaughton and Black 1973; Gay and Stewart 1974; Oke 1987). For croplands, the average midday $R_{c}$ was $15 \mathrm{~s} \mathrm{~m}^{-1}$ when using GEM and $35 \mathrm{~s} \mathrm{~m}^{-1}$ and when using the Jarvis scheme; thus, the estimates of $R_{c}$ from GEM are more consistent with observations such as those of Baldocchi (1992) whose measurements of $R_{c}$ over maize and wheat were 15 and $35 \mathrm{~s} \mathrm{~m}^{-1}$, respectively. Although no reports of $R_{c}$ for shrubland were found, the GEM-produced values (ranging between 300 and $400 \mathrm{~s} \mathrm{~m}^{-1}$ ) were significantly lower than those from the Jarvis scheme (ranging from 500 to $800 \mathrm{~s} \mathrm{~m}^{-1}$ ). Thus, it is quite clear that the two methods for determining $R_{c}$ produce very different results over grasslands and shrublands while producing similar results over croplands and forest. 
(a)

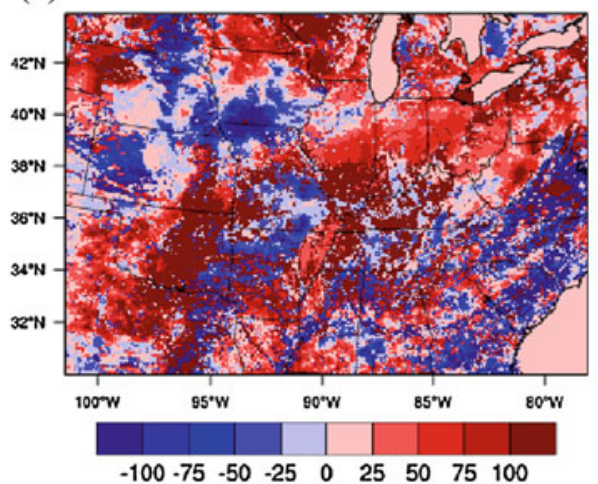

(c)

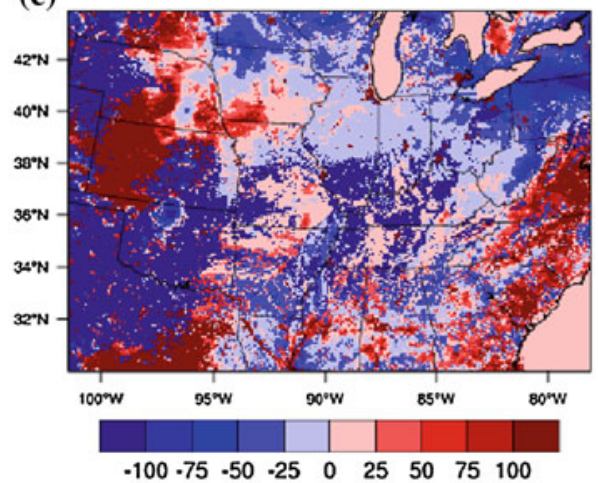

(b)

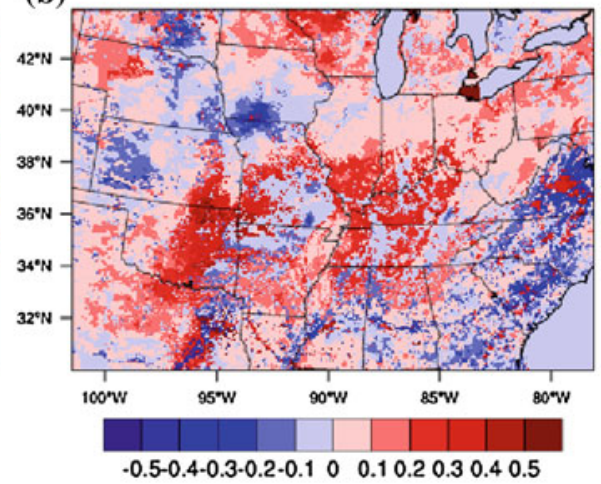

(d)

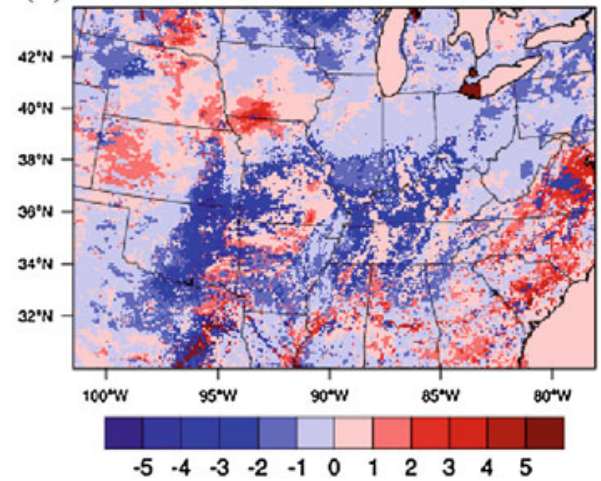

Fig. 3 The difference between the simulations with the Jarvis scheme and GEM at 1300 LST on 15 June 2002 is shown for: a latent heat flux $\left(\mathrm{W} \mathrm{m}^{-2}\right)$, b evapotranspiration $\left(\mathrm{mm} \mathrm{hr}^{-1}\right)$, c canopy resistance $\left(\mathrm{s} \mathrm{m}^{-1}\right)$, and $\mathbf{d}$ skin temperature $(\mathrm{K})$

\subsection{Verification of Canopy Resistance at the Niwot Ridge Ameriflux Site}

The Niwot Ridge Ameriflux site is located in the Roosevelt National Forest in the Rocky Mountains of central Colorado $\left(40^{\circ} 1^{\prime} 58^{\prime \prime} \mathrm{N}, 105^{\circ} 32^{\prime} 47^{\prime \prime} \mathrm{W}\right)$, and is dominated by subalpine forest with a leaf area index of $4.2 \mathrm{~m}^{2} \mathrm{~m}^{-2}$ and canopy height of 11.4 $\mathrm{m}$. The full suite of micrometeorological and soil measurements are collected on a half-hourly basis, and using these data, $R_{c}$ is calculated using the inverted PenmanMonteith formulation described by Turnipseed et al. (2003). Because $R_{c}$ estimates were available for only select days during June 2002, and the Niwot Ridge site is located outside of the model domain, the simulations with the Jarvis scheme and GEM were conducted using a one-dimensional column version of Noah. The simulations were for the 18-month period from 1 January 2001 to 30 June 2002 and used the same meteorological and forcing data required for driving HRLDAS (Chen et al. 2007).

A comparison of the midday averages of the observed and modelled $R_{c}, H$, and $L E$ (Fig. 5) showed clear differences. For example, although the estimates of $R_{c}$ from NoahGEM were slightly higher than those derived from the observations, they maintained the same temporal pattern. In contrast, $R_{c}$ derived from the Jarvis scheme had a nearly constant 

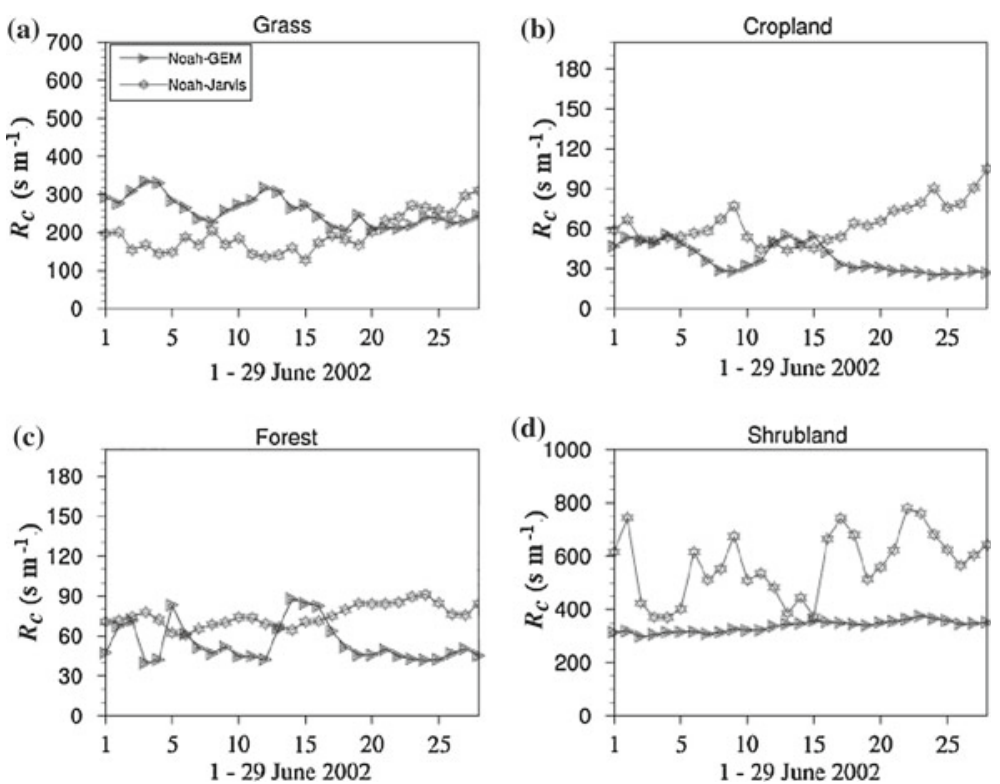

Fig. 4 Midday average (0900-1500 LST) canopy resistance for June 2002 over: a grass, b cropland, $\mathbf{c}$ forest, and $\mathbf{d}$ shrubland
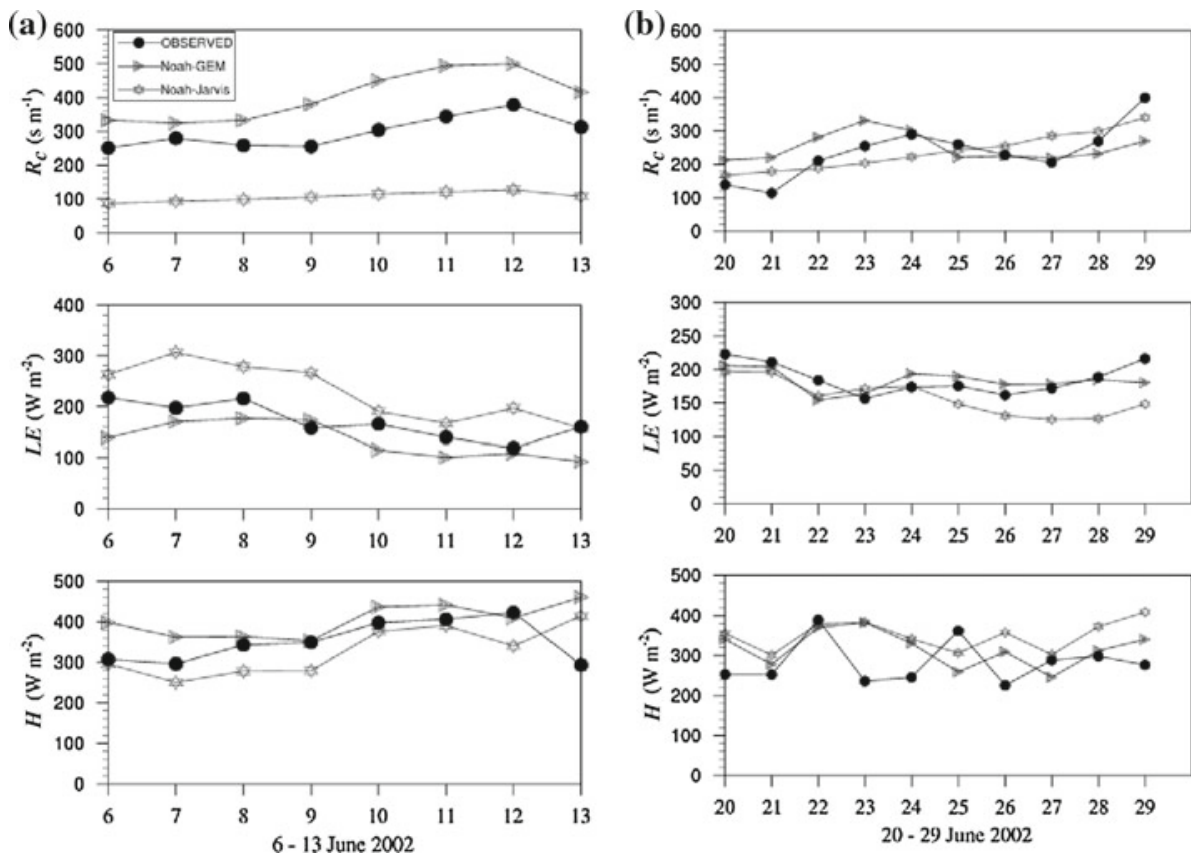

Fig. 5 Niwot Ameriflux site: midday average (0900-1500 LST) canopy resistance $\left(R_{C}\right)$, latent heat flux $(L E)$ and sensible heat flux $(H)$ from Jarvis and GEM and compared with the estimated $R_{C}, \mathbf{a} 6-13$ June 2002 and b 20-29 June 2002 

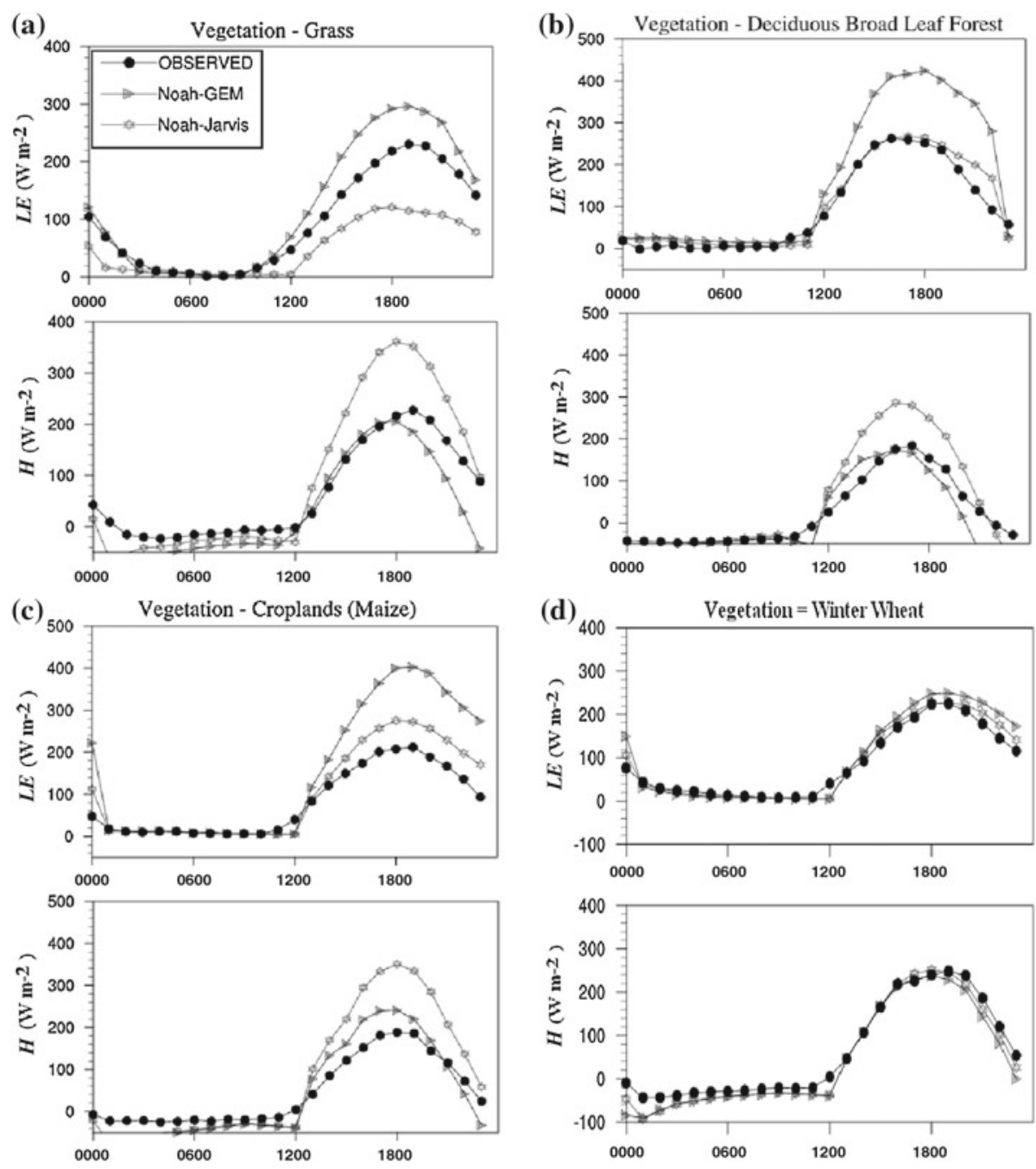

Fig. 6 Diurnal average cycle (June 2002) of latent and sensible heat fluxes over different observational sites: a Plevna, Kansas, b Duke hardwood forest, c Mead irrigated, and d average over two IHOP sites: Spivey and Conway Spring in Kansas constitute winter wheat vegetation types

value. For the period from 6 June through 13 June, $R_{c}$ derived from observations ranged between 230 and $300 \mathrm{~s} \mathrm{~m}^{-1}$ while the values from Noah-GEM ranged between 300 and $410 \mathrm{~s} \mathrm{~m}^{-1}$. The results from the Jarvis scheme save a value of approximately $100 \mathrm{~s} \mathrm{~m}^{-1}$. As a result, while there was a close agreement between the observed fluxes and the Noah-GEM output, the default version of Noah tended to overestimate $L E$ by $50 \mathrm{~W} \mathrm{~m}^{-2}$, on average. For the period from 20 June to 29 June, the discrepancy between the observed and modelled $L E$ was between 50 and $100 \mathrm{~W} \mathrm{~m}^{-2}$ when the Jarvis scheme was employed to estimate $R_{c}$. These results suggest that the Noah-GEM is better able to capture the diurnal and seasonal variations in both $R_{c}$ and the surface fluxes that are due to changing environmental conditions. 

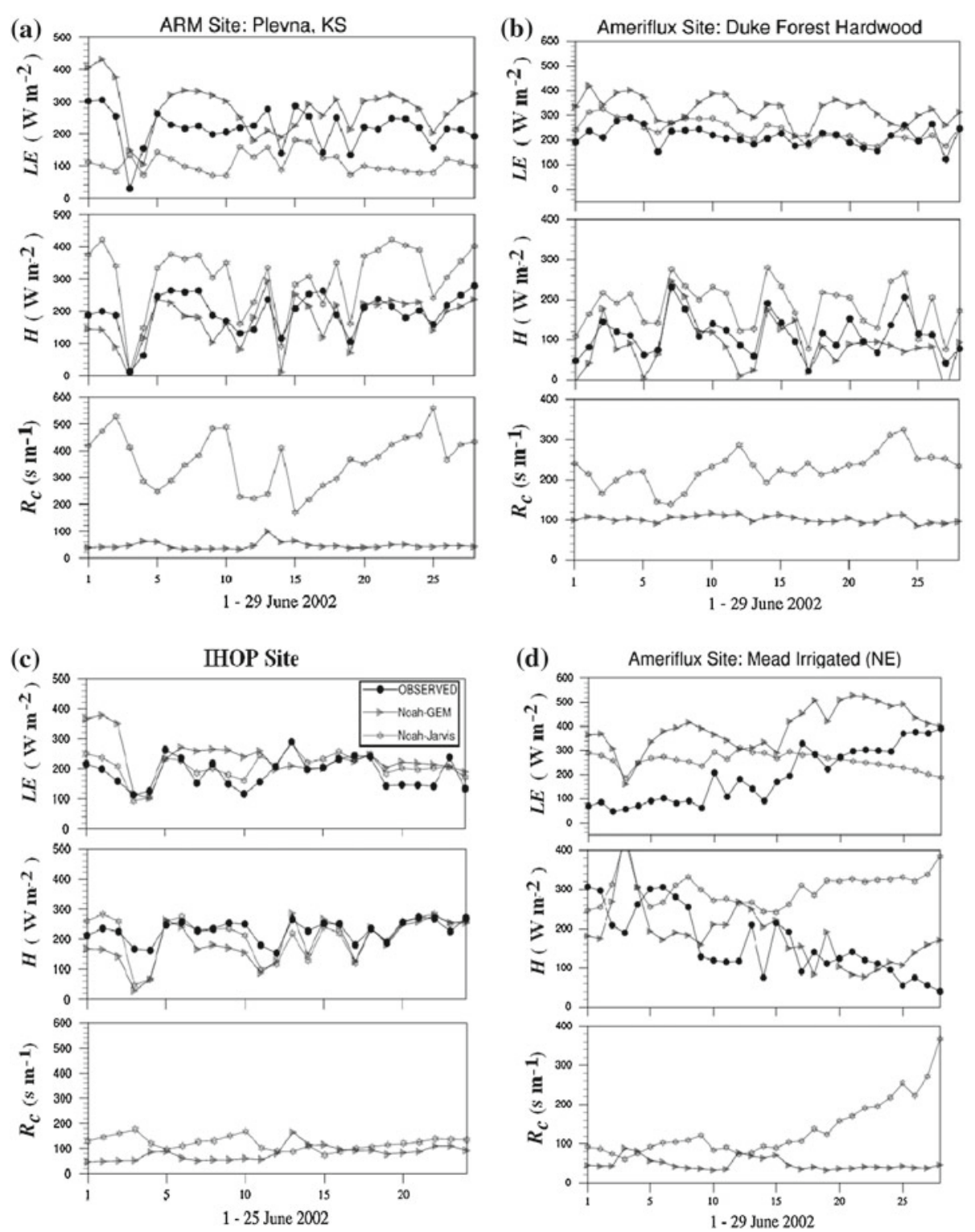

Fig. 7 Midday average for the June 2002 latent heat $(L E)$, sensible heat $(H)$ fluxes and canopy resistance $\left(R_{C}\right)$ over various observational sites: a Plevna grassland, Kansas, b Duke hardwood forest, $\mathbf{c}$ average over two IHOP winter wheat sites: Spivey and Conway Spring, Kansas, and d Mead, Nebraska. Observed (solid circle), GEM (closed triangle), Noah (open circle)

\subsection{Verification of Canopy Resistance in the Southern Great Plains Using ARM,} IHOP_2002, and Ameriflux Data

The model output from both the default version of Noah with Jarvis scheme and NoahGEM were compared to observations collected in the US Southern Great Plains during IHOP_2002 and at ARM and Ameriflux sites. Overall, for the region, it appears that 
Table 4 Bias and mean for soil moisture at level $1(50 \mathrm{~mm})$ and level $2(150 \mathrm{~mm})$ soil depth for Jarvis- and GEM for 14 May to 25 June 2002 IHOP observations

\begin{tabular}{lllll}
\hline Soil moisture (volumetric, $\mathrm{m}^{3} \mathrm{~m}^{-3}$ ) & \multicolumn{2}{l}{ Bias } & \multirow{2}{*}{ Mean observation } & Mean Jarvis/GEM \\
\cline { 2 - 3 } & Jarvis & GEM & \\
\hline Level 1 & -0.047 & -0.017 & 0.268 & $0.221 / 0.251$ \\
Level 2 & -0.071 & -0.035 & 0.302 & $0.231 / 0.267$ \\
\hline
\end{tabular}

Fig. 8 Averaged diurnal soil temperature cycle at $50 \mathrm{~mm}$ soil depth for June 2002 based on Jarvis and GEM and its comparison with observation over two different sites: a ARM site: Plevna station in Kansas (grass), b Ameriflux site: Mead site (maize)
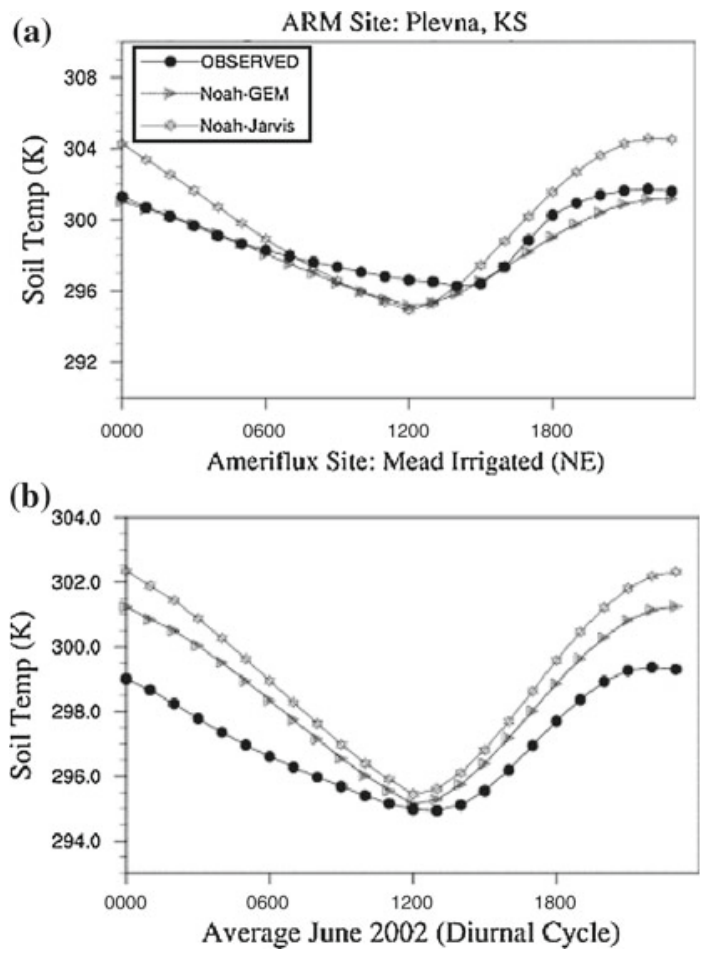

Noah-GEM performs better in capturing the spatial variability in the turbulent fluxes than does the default Noah using the Jarvis scheme. This is particularly evident in the eastern part of the IHOP_2002 domain, which was comprised of several different vegetation types and demonstrated significant spatial variability in both $H$ and $L E$ (LeMone et al. 2007a,b; Alfieri et al. 2009).

Using composites of the diurnal cycle of the turbulent fluxes for June 2002 (Fig. 6), the modelled and observed fluxes were compared. The data were analysed for four different vegetation types: grassland (ARM facility at Plevna, Kansas), deciduous forest (Duke Hardwood Forest Ameriflux site), maize (Mead, Nebraska Ameriflux site), and winter wheat (the average of the IHOP_2002 sites near Spivey, Kansas and Conway Spring, Kansas). Although the modelled $H$ showed reasonable agreement with the observations, the estimates of $L E$ from Noah-GEM were between 50 and $200 \mathrm{~W} \mathrm{~m}^{-2}$ greater than the observations from both the ARM facility and Ameriflux sites. There was little difference between the modelled and observed fluxes for either version of Noah at the winter wheat sites. 
Table 5 Bias and mean for latent $(L E)$ and sensible heat $(H)$ flux $\left(\mathrm{W} \mathrm{m}^{-2}\right)$ over two IHOP sites consist of grass (station 2 and 8) for Jarvis- and GEM for 14 May to 25 June 2002 IHOP observations

\begin{tabular}{|c|c|c|c|c|c|c|c|}
\hline & \multicolumn{2}{|l|}{ Bias } & \multicolumn{3}{|c|}{ Standard deviation } & \multirow{2}{*}{$\begin{array}{l}\text { Mean } \\
\text { observation }\end{array}$} & \multirow{2}{*}{$\begin{array}{l}\text { Mean } \\
\text { Jarvis/GEM }\end{array}$} \\
\hline & Jarvis & GEM & Obs & Jarvis & GEM & & \\
\hline \multicolumn{8}{|c|}{ IHOP sites 2 and 8 (grassland) } \\
\hline$L E\left(\mathrm{~W} \mathrm{~m}^{-2}\right)$ & 46.39 & -14.54 & 68.7 & 111.8 & 68.4 & 63.18 & $109.6 / 77.7$ \\
\hline$H\left(\mathrm{~W} \mathrm{~m}^{-2}\right)$ & -11.94 & 15.66 & 106.8 & 128.3 & 165.4 & 62.12 & $50.1 / 77.8$ \\
\hline \multicolumn{8}{|c|}{ IHOP sites 5 and 6 (wheat) } \\
\hline$L E\left(\mathrm{~W} \mathrm{~m}^{-2}\right)$ & 7.75 & 16.12 & 86.3 & 92.0 & 104.3 & 83.20 & $91.0 / 99.3$ \\
\hline$H\left(\mathrm{~W} \mathrm{~m}^{-2}\right)$ & -14.46 & -21.76 & 117.9 & 127.6 & 120.1 & 63.34 & $48.9 / 41.6$ \\
\hline
\end{tabular}

Fig. 9 Hourly volumetric soil moisture comparison between Noah and GEM over Oklahoma Mesonet data averaged over 65 Mesonet stations. The upper panel shows the soil moisture at $50 \mathrm{~mm}$ and the lower panel shows soil moisture at $150 \mathrm{~mm}$; (dark solid line) observations, (solid line), GEM (light dashed line), and the Jarvis scheme (dark dashed line)
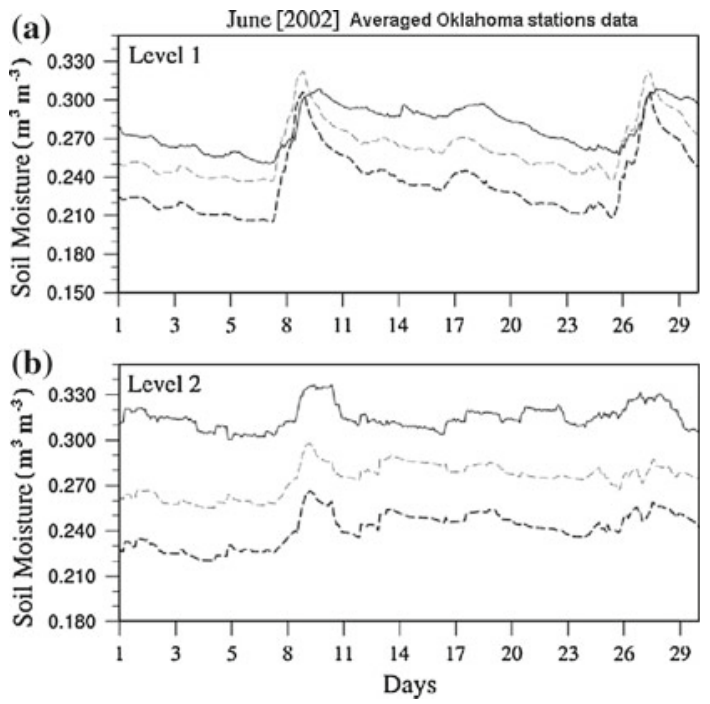

Focusing on midday averages for June 2002, the response of $H$ and $L E$ to variations in $R_{C}$ was evaluated (Fig. 7). Although observations of $R_{c}$ were unavailable at the ARM and Duke Hardwood Forest site, a comparison of the values from GEM and the Jarvis scheme showed that the former produced lower and less variable $R_{c}$ estimates. A similar analysis performed using the average of the two IHOP_2002 winter wheat sites and the Mead, Nebraska Ameriflux site showed the two methods for calculating $R_{c}$ yielded similar results. The difference in the $R_{c}$ measurements were somewhat larger over maize than over winter wheat, however. Despite the modest variability in $R_{c}$, Noah-GEM better reproduces day-to-day patterns in energy fluxes than does the default Noah. For instance, the observed increasing trend in $L E$ and decreasing trend in $H$ was captured by Noah-GEM model but not the Jarvis scheme.

\subsection{Verification of Soil Moisture and Temperature with ARM, Ameriflux and Oklahoma Mesonet Data}

One of the principal reasons for using HLDAS is to obtain accurate soil moisture and soil temperature information, which are of value in a variety of applications including the initialising the soil states in mesoscale NWP models (e.g. Trier et al. 2004, 2008; Holt et al. 2006; 

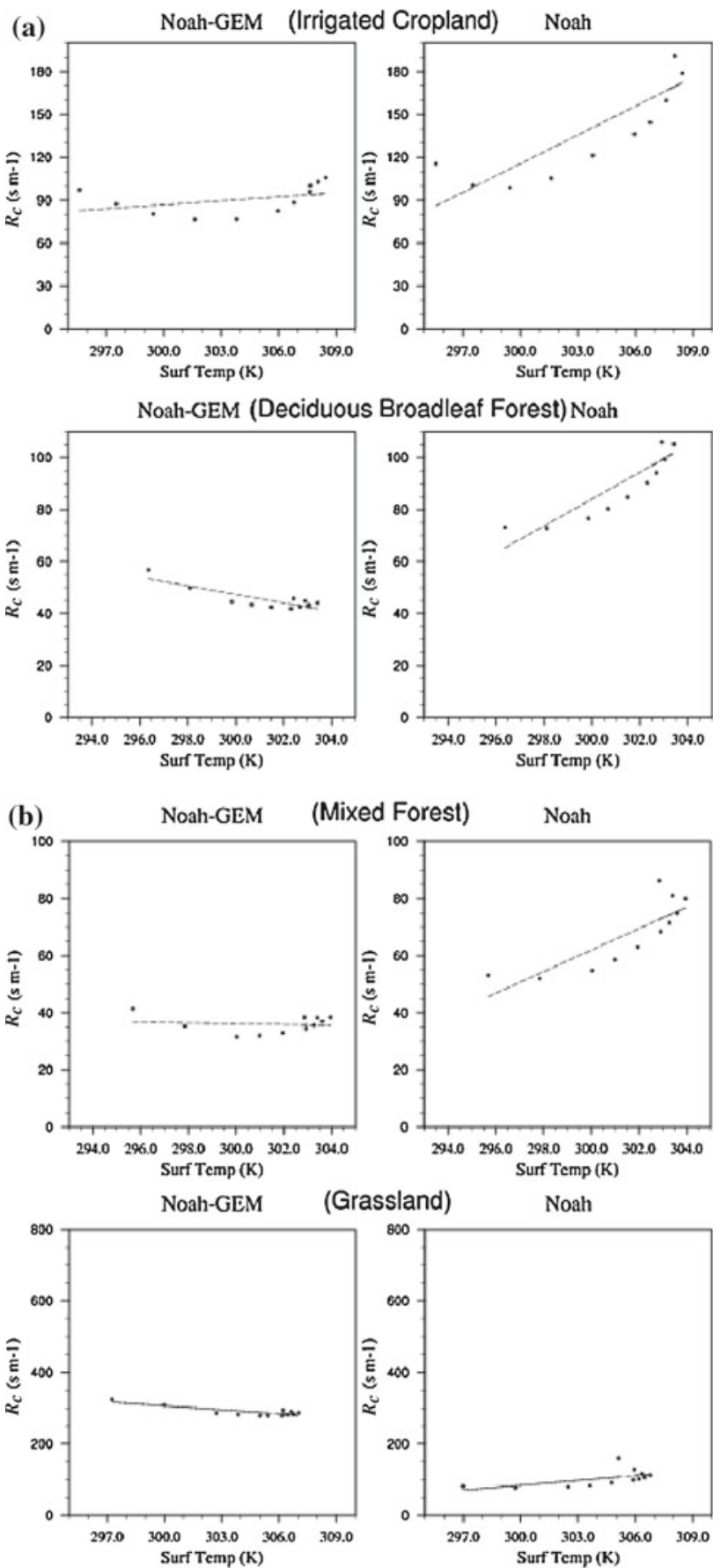

Fig. 10 a Daytime (1300 LST) correlation between canopy resistance and surface temperature over irrigated cropland (top) and deciduous broadleaf forest (bottom). b Same as a but for mixed forest (top) and grassland (bottom) 
Niyogi et al. 2006). Using data from the Plevna, Kansas ARM facility and Mead, Nebraska Ameriflux site, which had continuous data for June 2002, the modelled and observed soil temperature were compared. The composite of the diurnal cycle of the 50 - mm soil temperature are shown in Fig. 7 and summary statistics are provided in Table 4. Compared to the output from default version of Noah using the Jarvis scheme, the bias in the estimates of soil temperature from Noah-GEM was reduced by $50 \%$ at the Plevna site. A smaller decrease in the bias was also seen at the Mead, Nebraska Ameriflux site. Overall, the predicted soil temperature from Noah-GEM was in good agreement with observations. A similar verification of the hourly soil moisture data at two depths, 0.05 and $0.15 \mathrm{~m}$, was conducted using the average of the data from all of the Oklahoma Mesonet stations for June 2002. While the default model tended to underestimate soil moisture at both levels, Noah-GEM provided better estimates of soil moisture (Fig. 8; Table 5).

\subsection{Relationship Between Canopy Resistance and Surface Temperature}

A detailed surface and boundary-layer analysis was conducted by LeMone et al. (2007a,b, 2010a,b) using IHOP_2002 data. Stomatal resistance estimates from observed humidity, transpiration, radiation, and leaf temperature using a steady-state porometer were reported and showed that the resistance decreased with increasing leaf temperature, which is typical for unstressed plants during daylight hours. By design, Noah does not explicitly calculate leaf temperature, but an effective surface temperature is calculated in the model (Noilhan and Planton 1989). This effective surface temperature was compared to the values from LeMone et al. (2007a,b), and Fig. 9a and b shows the relation between $R_{c}$ and surface temperature over different vegetation types. The canopy resistance derived from GEM was consistent with the observations reported in LeMone et al. (2007a,b), whereas the Jarvis scheme demonstrated the opposite behaviour (Fig. 10).

\section{Conclusions}

The motivation for this study was to compare the default version of Noah, which is widely used for operational weather prediction, regional climate modelling, and research community, with a version that uses a physically-based model for determining $R_{c}$. Our study investigated the impact of incorporating the photosynthesis-based GEM into Noah on the ability of the land-surface model to represent surface energy fluxes, soil moisture and soil temperature. Based on the results of this work, it was concluded that Noah-GEM is better able to capture both diurnal and long-term variability in $R_{c}$ over differing vegetation types as compared to the Jarvis scheme. As a result, Noah-GEM was better able to reproduce the observed turbulent fluxes than the default version of the model. It also produced significantly better estimates of the soil moisture at the $0.05-\mathrm{m}$ and $0.15-\mathrm{m}$ levels. Thus, Noah-GEM is superior to the default version of the model that uses the Jarvis scheme. Since plans involve the coupling of Noah-GEM to mesoscale models, such as the Weather Research and Forecasting (WRF) model (Kumar et al. 2008; Chang et al. 2009), our results indicate that GEM is able to be effectively combined with Noah and with mesoscale models.

Acknowledgements The authors would like to acknowledge the support from the DOE ARM Program (08ER64674), NOAA JCSDA (NA06NES4400013), NASA THP (NNX08AV80G, NNX08AU67), NCAR USWRP STEP, the NCAR Water System (Grant NSF 01) and STEP programs, NSF (ATM-0296159, ATM-0236885, and OCI-0753116), NASA GWEC (NNG05GB41G), and NASA Headquarters through the NASA Earth and Space Science Fellowship (NNX07AN67H). 


\section{References}

Alapaty K, Pleim J, Raman S, Niyogi D, Byun D (1997) Simulation of atmospheric boundary layer processes using local- and nonlocal-closure schemes. J Appl Meteorol 36: 214-233

Alfieri JG, Niyogi D, Blanken PD, Chen F, LeMone MA, Ek M, Mitchell K, Kumar A (2008) Estimation of the minimum canopy resistance for croplands and grasslands using data from the 2002 International $\mathrm{H}_{2} \mathrm{O}$ Project. Mon Weather Rev 136: 4452-4469

Alfieri JG, Niyogi D, Zhang H, LeMone MA, Chen F (2009) Quantifying the spatial variability of the surface fluxes using data from the 2002 International $\mathrm{H}_{2} \mathrm{O}$ Project. Boundary-Layer Meteorol 133: 323-341

Anderson N, Norman J, Meyers T, Diak G (2000) An analytical model for estimating canopy transpiration and carbon assimilation fluxes based on canopy light use efficiency. Agric For Meteorol 101: 265-289

Avissar R (1993) Observations of leaf stomatal conductance at the canopy scale: an atmospheric modeling perspective. Boundary-Layer Meteorol 64: 127-148

Baldocchi D (1992) A lagrangian random-walk model for simulating water vapour, $\mathrm{CO}_{2}$, and sensible heat flux densities and scalar profiles over and within a soybean canopy. Boundary-Layer Meteorol 61: 113-144

Baldocchi DD, Law BE, Anthoni PM (2000) On measuring and modeling energy fluxes above the floor of a homogeneous and heterogeneous conifer forest. Agric For Meteorol 102: 187-206

Ball J, Woodrow I, Berry J (1987) A model predicting stomatal conductance and its contribution to the control of photosynthesis under different environmental conditions. In: Biggens J (ed) Progress in photosynthesis research, vol IV. Martinus Nijhoff Pub., Dordrecht, pp 221-224

Beljaars AC, Viterbo P, Miller MJ, Betts AK (1996) The anomalous rainfall over the United States during July 1993: sensitivity to land surface parameterization and soil moisture anomalies. Mon Weather Rev 124: $362-383$

Betts AK, Chen F, Mitchell KE, Janjić ZI (1997) Assessment of the land surface and boundary layer models in two operational versions of the NCEP Eta model using FIFE data. Mon Weather Rev 125: 2896-2916

Brock FV, Crawford KC, Elliott RL, Cuperus GW, Stadler SJ, Johnson HL, Eilts MD (1995) The Oklahoma Mesonet, a technical overview. J Atmos Ocean Technol 12: 5-19

Calvet J, Noilhan J, Roujean J, Bessemoulin P, Cabelguenne M, Olioso A, Wigneron J (1998) An interactive vegetation SVAT model tested against data from six contrasting sites. Agric For Meteorol 92: 73-95

Chang H, Kumar A, Niyogi D, Mohanty UC, Chen F, Dudhia J (2009) The role of land surface processes on the mesoscale simulation of the July 26, 2005 heavy rain event over Mumbai, India. Glob Planet Change 67: $87-103$

Chen F, Dudhia J (2001) Coupling an advanced land-surface/hydrology model with the Penn State/NCAR MM5 modeling system. Part I: Model implementation and sensitivity. Mon Weather Rev 129: 569-585

Chen F et al (1996) Modeling of land-surface evaporation by four schemes and comparison with FIFE observations. J Geophys Res 101: 7251-7268

Chen F, Janjic Z, Mitchell K (1997) Impact of atmospheric-surface layer parameterizations in the new landsurface scheme of the NCEP mesoscale Eta numerical model. Boundary-Layer Meteorol 85: 391-421

Chen F, Manning KW, LeMone MA, Trier SB, Alfieri JG, Roberts R, Wilson J, Tewari M, Niyogi D, Horst TW, Oncley SP, Basara JB, Blanken PD (2007) Evaluation of the characteristics of the NCAR high-resolution land data assimilation system during IHOP_2002. J Appl Meteorol Clim 46: 694-713

Collatz GJ, Ball JT, Grivet C, Berry JA (1991) Physiological and environmental regulation of stomatal conductance, photosynthesis and transpiration: a model that includes a laminar boundary layer. Agric For Meteorol 54: 107-136

Collatz J, Ribas-Carbo M, Berry J (1992) Coupled photosynthesis-stomatal conductance model for leaves of C4 plants. Aust J Plant Physiol 19: 519-538

Cooter E, Schwede D (2000) Sensitivity of the National Oceanic and Atmospheric Administration multilayer model to instrument error and parameterization uncertainty. J Geophys Res 105: 6695-6704

Cosby BJ, Hornberger GM, Clapp RB, Ginn TR (1984) A statistical exploration of the relationships of soil moisture characteristic to the physical properties of soils. Water Resour Res 20: 682-690

Dorman JL, Sellers PJ (1989) A global climatology of albedo, roughness length and stomatal resistance for atmospheric general circulation models as represented by the simple biosphere model (SiB). J Appl Meteorol 28: 833-855

Ek M, Mahrt L (1991) OSU 1-D PBL model user's guide version 1.04. Department of Atmospheric Science, Oregon State University, Corvallis, $120 \mathrm{pp}$

Ek MB, Mitchell KE, Lin Y, Rogers E, Grunmann P, Koren V, Gayno G, Tarpley JD (2003) Implementation of Noah land surface model advances in the National Centers for Environmental Prediction operational mesoscale Eta model. J Geophys Res 108:8851

Gay LW, Stewart JB (1974) Energy balance studies in coniferous forest. Report No. 23, Instit. Hydrol., Natural Enviro. Res. Council, Wallingford, Berks 
Holt T, Niyogi D, Chen F, LeMone MA, Manning K, Qureshi AL (2006) Effect of land-atmosphere interactions on the IHOP 24-25 May 2002 convection case. Mon Weather Rev 134: 113-133

Jacquemin B, Noilhan J (1990) Sensitivity study and validation of a land surface parameterization using the HAPEX-MOBILHY dataset. Boundary-Layer Meteorol 52: 93-134

Jarvis PG (1976) The interpretation of the variation in leaf water potential and stomatal conductance found in canopies in the field. Philos Trans R Soc Lond B 273: 593-610

Kim J, Verma S (1990) Carbon dioxide exchange in a temperate grassland ecosystem. Boundary-Layer Meteorol 52: 135-149

Kumar A, Chen F, Niyogi D, Alfieri J, Manning K, Ek M, Mitchell K (2008) Using photosynthesis-based canopy resistance model and new MODIS-based data to improve the presentation of vegetation transpiration in the Noah land surface model. In: 22nd conference of hydrology, New Orleans, LA. Amer. Meteor. Soc., J3.1. http://ams.confex.com/ams/pdfpapers/131425.pdf

LeMone MA, Chen F, Alfieri J, Cuenca R, Hagimoto Y, Blanken P, Niyogi D, Kang S, Davis K, Grossman R (2007a) NCAR/CU surface, soil, and vegetation observation network during the IHOP_2002 field campaign. Bull Am Meteorol Soc 88: 65-81

LeMone MA, Chen F, Alfieri JG, Tewari M, Geerts B, Miao Q, Grossman RL, Coulter RL (2007b) Influence of land cover, soil moisture, and terrain on the horizontal distribution of sensible and latent heat fluxes and boundary layer structure in southeast Kansas during IHOP_2002 and CASES-97. J Hydrometeorol 8: 68-87

LeMone MA, Chen F, Tewari M, Dudhia J, Geerts B, Miao Q, Coulter RL, Grossman RL (2010a) Simulating the IHOP_2002 fair-weather CBL with the WRF-ARW-Noah modeling system. Part I: Surface fluxes and CBL structure and evolution along the eastern track. Mon Weather Rev 138(3): 722-744

LeMone MA, Chen F, Tewari M, Dudhia J, Geerts B, Miao Q, Coulter RL, Grossman RL (2010b) Simulating the IHOP_2002 fair-weather CBL with the WRF-ARW-Noah modeling system. Part II: Structures from a few kilometers to $100 \mathrm{~km}$ across. Mon Weather Rev 138(3): 745-764

Leuning R (1995) A critical appraisal of a combined stomatal-photosynthesis model for C3 plants. Plant Cell Environ 18: 339-355

Mahrt L, Ek K (1984) The influence of atmospheric stability on potential evaporation. J Clim Appl Meteorol 23: $222-234$

McNaughton KG, Black TA (1973) A study of evapotranspiration from a Douglas-fir forest using the energy balance approach. Water Resource Res 9: 1579-1590

Miller DA, White RA (1998) A conterminous United States multilayer soil characteristic data set for regional climate and hydrology modeling. Earth Interact 2. http://EarthInteraction.org

Mitchell KE (2005) Pre-implementation testing of Noah 2.7.1 in the NCEP Global Forecast System (GFS). WRF land modeling working workshop, 13-15 Sept 2005, Boulder, CO

Mitchell K et al (2004) The multi-institution North American Land Data Assimilation System (NLDAS): utilizing multiple GCIP products and partners in a continental distributed hydrological modeling system. J Geophys Res 109. doi:10.1029/2003JD003823

Monteith JL (1965) Evaporation and environment. Symp Soc Exp Biol 19: 205-224

Nemani RR, Running SW (1989) Estimation of regional surface resistance to evapotranspiration from NDVI and thermal-IR AVHRR data. J Appl Meteorol 28: 276-284

Niyogi D, Raman S (1997) Comparison of four different stomatal resistance schemes using FIFE data. J Appl Meteorol 36: 903-917

Niyogi D, Raman S, Alapaty K (1998) Comparison of four different stomatal resistance schemes using FIFE observations. Part 2: Analysis of terrestrial biosphere atmosphere interactions. J Appl Meteorol 37 : 1301-1320

Niyogi D, Holt T, Zhong S, Pyle PC, Basara J (2006) Urban and land surface effects on the 30 July 2003 mesoscale convective system event observed in the southern Great Plains. J Geophys Res 111:D19107. doi:10.1029/2005JD006746

Niyogi D, Alapaty K, Raman S, Chen F (2008) Development and evaluation of a coupled photosynthesisbased gas-exchange evapotranspiration model (GEM) for mesoscale weather forecasting applications. J Appl Meteorol Clim 48: 349-368

Noilhan J, Planton S (1989) A simple parameterization of land surface processes for meteorological models. Mon Weather Rev 117: 536-549

Oke TR (1987) Boundary layer climates. Methuen, London, $151 \mathrm{pp}$

Pan H-L, Mahrt L (1987) Interaction between soil hydrology and boundary-layer development. BoundaryLayer Meteorol 38: 185-202

Pielke RA Sr, Niyogi D (2010) The role of landscape processes within the climate system. In: Otto J-C, Dikau R (eds) Landform-structure, evolution, process control. Lecture Notes in Earth Sciences 115. Springer-Verlag, Berlin, pp 67-85. doi:10.1007/978-3-540-75761-0_5 
Sellers P, Randall D, Collatz J, Berry J, Field C, Dazlich D, Zhang C, Collelo G, Bounous A (1996a) A revised land surface parameterization (SiB2) for atmospheric GCMs: model formulation. J Clim 9: 676-705

Sellers P, Berry J, Collatz J, Field C, Hall F (1996b) Canopy reflectance, photosynthesis, and transpiration. III. A reanalysis using improved leaf models and a new canopy integration scheme. Remote Sens Environ 42: $187-216$

Shafer MA, Fiebrich CA, Arndt DS, Fredrickson SE, Hughe TW (2000) Quality assurance procedures in the Oklahoma Mesonet. J Atmos Ocean Technol 17: 474-494

Trier S, Chen F, Manning K (2004) A study of convection initiation in a mesoscale model using high-resolution land surface initiation conditions. Mon Weather Rev 132: 2954-2976

Trier S, Chen F, Manning K, LeMone MA, Davis C (2008) Sensitivity of the simulated PBL and precipitation to land surface conditions for a 12-day warm-season convection period in the central United State. Mon Weather Rev 136: 2321-2343

Turnipseed AA, Anderson DE, Blanken PD, Baugh W, Monson RK (2003) Airflows and turbulent flux measurements in mountainous. Terrain: Part 1. Canopy and local effects. Agric For Meteorol 119: 1-21

Weckwerth TM et al (2004) An overview of the international $\mathrm{H}_{2} \mathrm{O}$ project (IHOP_2002) and some preliminary highlights. Bull Am Meteorol Soc 85: 253-277

Wilson KB et al (2002) Energy partitioning between latent and sensible heat flux during the warm season at FLUXNET sites. Water Resour Res 38:1294 